After intravenous injection methyldopa's effect is slow, while debrisoquine, like guanethidine, is contraindicated because it causes transient hypertension. So pentolinium still has much to commend it when quick reduction of bloodpressure is needed. The one other remaining use for a ganglion blocker is for combating the diarrhoea caused by a sympathetic-blocking drug.

Because it is said to cause less reduction of renal blood flow methyldopa is probably the drug of choice in hypertension with renal impairment ${ }^{3}$ and also in toxaemia of pregnancy, ${ }^{4}$ as it might be expected to have a more favourable effect on uterine blood flow than the other sympatholytic drugs. While reserpine, guanethidine, and to a less extent methyldopa deplete the myocardial and peripheral vascular stores of catecholamines, bethanidine ${ }^{5}$ and debrisoquine do not have this effect, and they might therefore be selected when there is complicating heart failure. Unfortunately all these drugs can cause retention of fluid, particularly in severe hypertension. Thiazides (or aldactone) both prevent this complication and potentiate the hypotension.

Individual patients vary in their blood-pressure response to pharmacologically similar drugs and their tolerance of sideeffects from them. It is for this reason rather than because it represents a specific advance in therapy that debrisoquine wins a place among the first-line drugs for the treatment of severe hypertension.

\section{Oesophageal Cancer}

The incidence of oesophageal cancer differs widely in different areas of the world. This suggests that environmental factors are of importance in its causation, and because food and beverages come into direct contact with the oesophagus it is tempting to assume that the environmental factors in question are dietary. However, experience in the laboratory with compounds of the nitrosamine class shows that such an assumption is unwise. Specific nitrosamines tend to induce cancer at specific sites, irrespective of the route by which they are administered. A number of agents of this class have been shown to induce oesophageal cancer in laboratory animals. ${ }^{1-3}$ The specificity is so striking-the oesophagus may be the only organ which responds to the carcinogenic effects of a particular compound ${ }^{4}$ - that it is now justifiable to make a direct search of the human environment for nitrosamines which induce oesophageal cancer in man. Obviously, such a search can best begin in a geographical area where oesophageal cancer is prevalent. The observations of the late Dr. R. J. W. Burrell $^{5}$ suggested that the Transkei region of South Africa may be suitable for this purpose. Here, oesophageal cancer is endemic among the Bantu population; not generally, but in isolated well-defined pockets. In these the morbidity rate for squamous carcinoma of the thoracic oesophagus may exceed 1 per 1,000 of the population each year, whereas in surrounding areas the disease is not seen. In affected persons the presence of carcinoma-in-situ lesions, distinct from the main tumour, suggests that the carcinogenic influence is potent. ${ }^{6}$ In some of these pockets the disease is more or less confined to males, in others to females.

In the Transkei oesophageal cancer has been increasing in incidence, after first becoming prevalent in $1943 .{ }^{5}$ Similar increases in incidence have been observed among the Bantu populations of other regions of South Africa. ${ }^{78}$ White persons and Asians living in the affected areas have not been involved in the increasing incidence of the disease. In the Transkei during the same period there seems to have been a steady falling off in the quality of crops. ${ }^{5}$ The male Bantu tends to spend long periods away from home, and during these periods may be exposed to special cancer hazards. One such hazard is "cidivici," a native beer brewed illicitly, sometimes in metal drums which previously contained petroleum asphalt, and sometimes with the addition of materials such as carbide or metal polish. ${ }^{\circ}$ Because of the uncontrollable nature of this type of exposure, Burrell and his colleagues confined their most recent study ${ }^{10}$ to persons, mostly women, who had not moved more than a few miles from their homes during the 15 years before death. The gardens of 29 persons who had died from verified oesophageal cancer were compared with those of a similar number who were free of cancer, the expert who examined the gardens being ignorant of the category to which the owner belonged. The "cancer" gardens proved strikingly less productive than the "cancer-free" gardens, and though signs of molybdenum deficiency were seen in all gardens they were more marked in the "cancer" gardens. A third striking finding was that a disease of maize known as "withered end" was seen in all 29 of the "cancer" gardens but in none of the others. Plant injection studies suggested that the crops were affected not solely by shortage of molybdenum but by a complex trace-element deficiency. Nevertheless, it proved possible to reduce the incidence of withered end, and to treble the maize crop, by treating seeds with sodium molybdate solution.

In the light of comments made in the B.M.f. ${ }^{11}$ concerning the significance of the apparent association between the zinc/ copper ratio in soil and cancer of the stomach, ${ }^{12}$ Burrell and his colleagues are careful to point out that any connexion between the agricultural differences in the gardens and the presence or absence of cancer is unlikely to be direct. Nevertheless, their findings command attention for two reasons. First, the differences between the "cancer" and "cancerfree" gardens are very marked, and, secondly, unlike the situation reported by P. Stocks and R. I. Davies ${ }^{12}$ in relation to stomach cancer, the association between the diet of the persons studied and their gardens is very close. Thus persons dependent on gardens with poor yields are more likely to consume less desirable foods such as the prickly vine tips from pumpkins and various edible weeds. A consequence of molybdenum deficiency in maize is a greater susceptibility to fungal infection. It is possible that some fungal toxins are oesophageal carcinogens, though there is no evidence for this at present. The most interesting suggestions made by Burrell and his co-workers refer to the possible effect of molybdenum

\footnotetext{
1 Druckrey, H., Preussmann, R., Schmähl, D., and Müller, M., Neturwissenschaften, 1961, 48, 134.

2 - Ibid., 1962, 49, 19 Steinhoff, D., Beuthner, H., Schneider, H., and Klärner, P., Arzneimittel-Forsch., 1963, 13, 320

- Boyland, E., Roe, F. J. C., Gorrod, J. W., and Mitchley, B. C. V., Brit. f. Cancer, 1964, 18, 265 .

${ }^{5}$ Burrell, R. J. W., F. natn. Cancer Inst., 1962, 28, 495.

- Oettlé, A. G., ibid., 1964, 33, 383.

${ }^{7}$ Higginson, J., Cancer (Philad.), 1951, 4, 1224.

' Jarvis, J. F., E. Afr. med. F., 1953, 30, 523.

- Burrell, R. J. W., S. Afr. med. F., 1957, 31, 401

10 Roach, W. A., and Shadwell, A., F. natn. Cancer Inst., 1966, 36, 201

${ }_{11}$ Brit. med. F., 1965, 1, 1.

12 Stocks, P., and Davies, R. I., Brit. F. Cancer, 1964, 18, 14

13 Hewitt, E. J., and Jones, E. W., F. Pomology Hort. Sci., 1947, 23, 254

14 Preussmann, R., Daiber, D., and Hengy, H. A., Nature (Lond.), 1964, 201, 502.

15 Young, M., and Russell, W. F., Spec. Rep. Ser. med. Res. Coun., 1926.

London.
16 Wynder, E. L., Bross, I. J., and Feldman, R. M., Cancer (Philad.), 1957,
10, 1300.
} 
deficiency on the production of nitrosamines. Molybdenum is essential for the reduction of nitrate in all higher plants, so that nitrate accumulates in the presence of molybdenum deficiency. ${ }^{13}$ In turn, the accumulation of nitrates increases the risk that oxides of nitrogen, which can react with secondary or tertiary amines to produce nitrosamines, ${ }^{14}$ are formed in silage-making. The occurrence of $p$-methyl nitrosoaminobenzaldehyde in an "edible" mushroom, Clitocybe suaveolens, ${ }^{14}$ indicates that the formation of nitrosamines under natural conditions is more than just a theoretical possibility.

From time to time evidence has been put forward for associations between both tobacco smoking and alcohol consumption and oesophageal cancer in more developed countries. ${ }^{15} 16$ Neither alone nor in combination are these factors able to explain the epidemic of the disease in South Africa ${ }^{6}$ It is to be hoped that studies of the aetiology of the condition in areas such as the Transkei will provide information which will apply not only locally in Africa but generally to geographical regions where the disease is much less frequent.

\section{Chromosomes and Leukaemia}

If white blood cells taken from a patient with chronic granulocytic leukaemia are cultured, an abnormal chromosome will be found in many cases. This unusually small chromosome, at first thought to be an extra $\mathrm{Y}$ chromosome, was first described in 1960 by P. C. Nowell and D. A. Hungerford, ${ }^{1}$ of Philadelphia, in cultures of blood cells from a male patient. The abnormal chromosome was soon found in females also ${ }^{2}$ and was identified as belonging to pair number 21 or 22 . It was dubbed "Philadelphia one" $\left(\mathbf{P h}^{1}\right)$.

The $\mathrm{Ph}^{1}$ chromosome differs from a normal chromosome of pair 21 or 22 by a lack of the great part of the long arm, and in typical cases it is readily identified. It can be found in cultures of peripheral blood when immature granulocytes capable of division are present. Good preparations can be made without adding phytohaemagglutinin to the cultures, for the immature cells in chronic granulocytic leukaemia divide spontaneously, ${ }^{3}$ unlike the normal lymphocytes, which do not divide unless exposed to certain mitogenic stimuli. During remissions of the disease, when the blood picture is substantially normal, the $\mathrm{Ph}^{1}$ chromosome cannot be found in blood cultures, but it is still present in practically every dividing cell in the bone-marrow. Erythroblasts ${ }^{45}$ and megakaryocytes ${ }^{5}$ as well as the granulocyte precursors are now

1 Nowell, P. C., and Hungerford, D. A., f. nat. Cancer Inst., 1960, 25, 85.

2 Tough, I. M., Court Brown, W. M., Baikie, A. G., Buckton, K. E., Harnden, D. G., Jacobs, P. A., King, M. J., and McBride, J. A., Lancet, 1961, 1, 411.

s Speed. D. E., and Lawler, S. D., ibid., 1964, 1, 403

4 Clein, G. P., and Flemans, R. J., Brit. F. Haemat., 1966, 12. In press. Whang, J., Frei, E., Tiio, J. H., Carbone, P. P., and Brecher, G., Blood, 1963, 22, 664 .

6 Lawler, S. D., and Galton, D. A. G., Acta med. scand., 1966, Suppl No. 445 , p. 312 .

Galton, D. A. G., Proc. 10th Congress Internat. Soc. Haemat., Stock-

holm, 1964, 1965, p. 37.
\& Hall, B., Lancet, 1963, 1, 558.

- Krauss, S., Sokal, J. E., and Sandberg, A. A., Ann. intern. Med., 1964, 61, 625.

10 Hardisty, R. M., Speed, D. E., and Till, M., Brit. F. Haemat., 1964, 10, 551 .

$"$ Tjio, J. H., Carbone, P. P. Whang, J., and Frei, E., f. nat. Cancer Inst., 1966 36, 567.

1 Beaven, G. H., Stevens, B. L., Dance, N., and White, J. C., Nature (Lond.), 1963, 199, 1297. known to contain the $\mathrm{Ph}^{1}$ chromosome, indicating that the myeloid stem cell itself is affected. Other tissues do not show the abnormality; all the cells in cultures of skin fibroblasts, for example, contain a normal complement of normal chromosomes.

In most cases early in the disease only one member of the chromosome pair is abnormal, and all the remaining chromosomes are normal. As the disease progresses to the stage when it is resistant to treatment additional abnormalities appear. These vary from case to case, and in any one case change as the disease advances. ${ }^{6}$ Occasionally two $\mathrm{Ph}^{1}$ chromosomes are found. These additional abnormalities are sometimes found in untreated patients; most but not all of such patients respond badly to treatment.

The great majority of cases in which the $\mathrm{Ph}^{1}$ chromosome has been found were examples of classical chronic granulocytic leukaemia, but a few were atypical and showed clinical and haematological features of myelosclerosis ${ }^{7}$ or thrombocythaemia. The $\mathrm{Ph}^{1}$ chromosome has not yet been found in normal persons, though the number of observations is small. An abnormality very like it-perhaps identical-has been described in a case of Down's syndrome. ${ }^{8}$

Of much interest are patients, apparently suffering from chronic granulocytic leukaemia, whose myeloid cells do not contain the $\mathrm{Ph}^{1}$ chromosome. ${ }^{3}{ }^{9-11}$ These patients do not respond well to treatment, and it is therefore important to characterize this form of the disease. J. H. Tjio, P. P. Carbone, J. Whang, and E. Frei ${ }^{11}$ have compared some of the presenting clinical and haematological features of 60 patients with the $\mathrm{Ph}^{1}$ chromosome and 13 without it. The features examined were age, sex, spleen size, total leucocyte count, platelet count, haemoglobin concentration, leucocyte alkaline phosphatase concentration, and the ratio of granulocytic to erythroid cells in bone-marrow films. There were three children under 7 years in the $\mathrm{Ph}^{1}$-negative group, and none in the $\mathrm{Ph}^{1}$-positive group. The leucocyte counts of all but one of the $\mathrm{Ph}^{1}$-negative patients were below 150,000 / c.mm., but many $\mathrm{Ph}^{1}$-positive patients had higher counts. Most of the $\mathrm{Ph}^{1}$-positive patients also had higher platelet counts. None of the other presenting characteristics showed significant differences in the two groups.

The greatest difference was the poor response to treatment and short survival of the $\mathrm{Ph}^{1}$-negative patients. Complete or partial remissions occurred after treatment with busulphan, colcemid, or mercaptopurine in only 3 out of 10 trials in nine cases, compared with 20 patients who responded to treatment out of 21 trials in $\mathrm{Ph}^{1}$-positive cases. The median survival of the $13 \mathrm{Ph}^{1}$-negative patients was only 18 months, compared with 45 months for the $60 \mathrm{Ph}^{1}$-positive patients. Tjio and his colleagues believe that the $\mathrm{Ph}^{1}$-negative and positive groups constitute distinct entities, whose manifestations overlap.

Others have drawn attention to morphological features of the blood picture which differ in $\mathrm{Ph}^{1}$-negative and $\mathrm{Ph}^{1}$ positive cases and which were not evaluated by Tjio and his co-workers. The presence of monocytoid cells, morphological abnormalities of the granulocytes, and an excess of normoblasts are all features more likely to be prominent in $\mathrm{Ph}^{1}$-positive cases. Basophils, usually plentiful in $\mathrm{Ph}^{1}$ positive cases, are often absent in $\mathrm{Ph}^{1}$-negative cases. Redcell abnormalities, including the presence of haemoglobin $\mathrm{H}$, have also been reported. ${ }^{12}$

Thus the combination in an anaemic patient of gross splenomegaly, only moderate leucocytosis, a normal or low platelet count, a blood picture suggestive of but not quite typical of 